\title{
Gameful Self-Regulation: A Study on How Gamified Self-Tracking Features Evoke Gameful Experiences
}

\author{
Lobna Hassan \\ Gamification Group \\ University of Turku \\ lobna.hassan@tuni.fi
}

\author{
Nannan Xi \\ Gamification Group \\ Tampere University \\ nannan.xi@tuni.fi
}

\author{
Bahadir Gurkan \\ Gamification Group \\ Tampere University \\ bahadir.gurkan@tuni.fi
}

\author{
Jonna Koivisto \\ Gamification Group \\ Tampere University \\ jonna.koivisto@tuni.fi
}

\author{
Juho Hamari \\ Gamification Group \\ Tampere University \\ juho.hamari@tuni.fi
}

\begin{abstract}
Gamification has become one of the top engagement technology trends of recent times. It refers to designing and transforming systems, services, and activities to afford gameful experiences as good games do, commonly implemented through the utilization of familiar features from games. However, one of the persistent problems in academia and practice has been the lack of understanding of which systems features are more or less prone to facilitate which dimensions of the gameful experience. We investigate the relationships between user interaction with features related to goalsetting, self-tracking as well as prompts, and gameful experiences (accomplishment, challenge, competition, guidance, immersion, playfulness, and sociability) through a survey $(N=201)$ in a gamified exercise service. Goal-setting and prompt features were positively associated with most dimensions of the gameful experience whereas self-tracking features were negatively associated with immersion and sociability while positively associated with feelings of accomplishment.
\end{abstract}

\section{Introduction}

During recent years, it has become increasingly accepted that games can provide several kinds of cognitive, affective, social and motivational benefits $[9,13,53,54]$. The techno-social development termed 'gamification' $[6,13,21]$ has emerged as an attempt to harness these benefits on a larger scale [26, 36]. Gamification can be defined as a process of designing and transforming activities, systems, and services to afford similar psychological states and skills that good games provide. Such experiences of gamefulness would sustain engagement with activities in non-game contexts $[6,13,21]$. and thus, support user's motivation [13, 21, 30, 31, 36]. Gamification has, hence, been utilized pervasively especially across contexts where persistence and long-term continuance of activity are key to the realization of results; i.e. education, work, and health [23, 26, 27, 41, 44, 45].

A key to how gamification design often seeks to support the persistence and long-term continuance of activities is facilitating self-regulation; the self-tracking and correction of one's behavior in relation to a desired outcome that one wishes to attain [1]. Gamification design, commonly attempts to support several aspects of self-regulation [14, 27]; 1) Goal-setting, the process of determining desirable outcomes that individuals wish to attain [34], often facilitated in gamification through conscious objectives, leaderboards and badges (e.g., [14, 27]), 2) Self-tracking/monitoring of one's progress [1] is often facilitated in gamification through progress indicators and means of visualization such as graphs and progress bars (e.g., [18, 35] ), 3) Prompts that nudge individuals to continue to work towards their set goals, commonly facilitated in gamification in the form of reminders or suggestions [39, 48].

Prior research indicates that gamification can provide positive cognitive, affective, social, and motivational outcomes $[18,26]$ as well as support goal attainment, often through self-regulation. However, little is known about how, and through which features gamification and system design in general can lead to the gameful experience that gamification is thought to facilitate. The aim of this research is to investigate how gamification (operationalized as goal-setting, selftracking, and prompts features) leads to gameful experiences (i.e. accomplishment, challenge, 
competition, guided, immersion, playfulness, and social experience). We employ survey data gathered among users $(\mathrm{N}=201)$ of a gamified exercise app. This knowledge supports design of systems in general, and gamification applications in specific, that are better able to support individuals in their endeavors on the long run through inducing appropriate experiences.

\section{Background}

\subsection{Gamefulness}

To motivate engagement with activities that may not be inherently inviting, such as exercise [18] or routine work activities [50], there has been a pervasive effort to make these activities, and the systems and services employed around them, more game-like through several techniques [13]: gamification [21, 31], exergames [41], serious games [28], game-based learning $[17,24]$ games-with-a-purpose/human computation [37, 49], quantified-self (e.g. [14, 18]), and persuasive technologies/behavior change systems [55]; all of which generally belong to the larger class of motivational information systems [26]. The goal of such 'gamification' and technological developments is commonly to create a 'gameful experience' and consequently affect behavior in a positive way $[6,21$, $22,30]$. Gamefulness is, hence, key to the success of these systems and their ability to motivate individuals.

While traditional understanding still often regards gaming as a pure leisure activity without further benefits to an individual, gamified and gameful services combine dimensions of hedonism and utility $[26,30,31]$. The goal in gameful system design is to employ gameful design practices, which would in turn induce gameful experiences [22]. The gameful experiences would then motivate and support the user of a gameful system to perform intended behaviors [31]. Hence, gameful systems always contain a goal that is external to system use itself, and consequently, the experiences produced by such systems are not limited merely to the enjoyment of using the system.

While "gamefulness" as a construct has been considered difficult to define for a long time [6, 21], the construct has generally referred to a latent idea of experiences related to playing games [6, 21, 31]. Gamefulness in the context of gamification and gameful systems has perhaps come to be more concretely conceptualized as an interactive state in which an individual is voluntarily motivated to pursue meaningful goals, under pre-known conditions and evaluation techniques [31]. Recently, instruments for measuring the gameful experience have been developed: Högberg et al. [22] conducted an extensive study to identify dimensions of gamefulness in gamified services. The work incorporated previous research on gamefulness from various fields through a literature review as well as a host of qualitative and quantitative confirmatory studies, leading to the identification of seven dimensions of gamefulness in gamified services as presented in Table 1 .

As these conceptualizations of gameful experiences are recent, the understanding of which types of gamification may give rise to which gameful experiences is lagging behind. Some preliminary work has been conducted in order to identify which gameful elements could be connected to which aspects of gameful experiences [2, 43, 51]. However, little is known about how the various gameful design elements affect the various dimensions of gameful experiences.

\subsection{Gameful self-regulation}

It is unintuitive to expect that all gamification features that entail different dynamics and mechanics would be equally suited to facilitate all the different dimensions of gameful experiences. For the purposes of more effective gameful designs, it is of value to understand which gamification features or feature categories may be better or less able to evoke certain dimensions of gamefulness.

Gamification features are often selected to facilitate self-regulation [10, 14]; a process of monitoring one's activity in relation to internal or external goals, so as to improve and correct one's behavior [1]. Self-regulation is thought to be a core aspect of human psychology through which individuals improve themselves, learn, or attain goals [1, 32, 52]. Successful self-regulation often depends on the frequency, consistency and accuracy of self-monitoring/tracking [1] as well as the goal-setting process individuals engage in [32] amongst other variables.

Goal setting; represents a process of determining and pursuing desirable end states that individuals wish to attain [34]. All individuals engage in goal-setting consciously or unconsciously, but perhaps conscious goal-setting is the most effective in terms of selfdevelopment [32, 33]. One of the core strengths of gamification and motivational design is directing individuals along this process, arguably through the gameful experience $[10,21]$. Research has investigated commonly employed features of gamification and the extent to which they support goal-setting, for example, leaderboards in learning [29] rewards and outcomes $[16,37,39]$ and largely, which categories of gamification features may be preferred by which individuals depending on their goal-setting tendencies [14]. Theory has hence emerged on the connections between goal-setting and gamification [10]. 
Table 1. Gamefulness dimensions according to Högberg et al. [22]

\begin{tabular}{|c|c|}
\hline Gamefulness dimension & Definition \\
\hline Accomplishment & The drive for attainment of goals and completion of tasks \\
\hline Challenge & A test of one's ability in which there is a drive for hard work to achieve the challenge \\
\hline Competition & The drive to best one's self or others and attain a desirable outcome \\
\hline Guided & $\begin{array}{l}\text { Feelings of being guided as to how, through what, and when can the goals of the gamified service } \\
\text { be attained }\end{array}$ \\
\hline Immersion & Absorption in the activity at hand to the exclusion of anything outside of it \\
\hline Playfulness & $\begin{array}{l}\text { Feelings of voluntary engagement with imaginative or exploratory activities that have clearly } \\
\text { defined rules }\end{array}$ \\
\hline Social experience & Feelings of social presence associated with real or imaginary social actors in service \\
\hline
\end{tabular}

Self-tracking/monitoring; involves the conscious tracking of one's behavior and variables of interest [47]. The idea of self-tracking in order to consciously adjust and improve performance has perhaps been most notably popularized in recent years by the quantifiedself movement that advocated that such self-tracking is core to self-improvement $[3,35,48]$. Notable gamification features that facilitate self-tracking include progress bars that summarize performance [14] as well as feedback mechanics [18] amongst other features. Research indicates that self-tracking of activity in gamified contexts can provide users benefits [18], create enjoyable experiences of flow [20], as well as motivate engagement with the gamified activity [3, 15, 37, 39].

Prompts; while goal-setting [34] and self-tracking [3] have been found very useful to improving human behavior and its outcomes, research indicates that individuals do not always consciously choose to follow these strategies [52]. Additionally, individuals may not often know what is it that they are supposed to do next to attain their set goals without some external direction or information [35]. Prompts and suggestions are often employed in gamification for these purposes. They remind and nudge individuals towards further engagement with the gamified systems as well as the underlying activity that the system is attempting to support. Research on gamification has indicated that notifications and prompts are one of the most appreciated features by users [39]. Similar findings have been obtained with regards to behavioral suggestions to promote desired behavior [48].

The implicit assumption in this research is that gamification through these features associates with gamefulness or similar positive experiences [26]. Many of the outlined gamification features indeed do positively associate with positive affect [18], and flow experiences [20], strengthening the implicit assumptions that gamification features associate with gamefulness. Nonetheless, research has not directly investigated whether gamification features that support self-regulation actually associate with experiences of gamefulness in general, or with which of the individual dimensions of gamefulness in specific. The question remains as to what dimensions of gameful experiences do gamification features that support self-regulation (in terms of goal-setting, self-tracking, and prompts) promote in users. To answer this question, and based on a scarcely available literature, we explored all possible associations between the 3 categories of gamification design features and the seven dimensions of the gameful experience as presented in Figure 1.

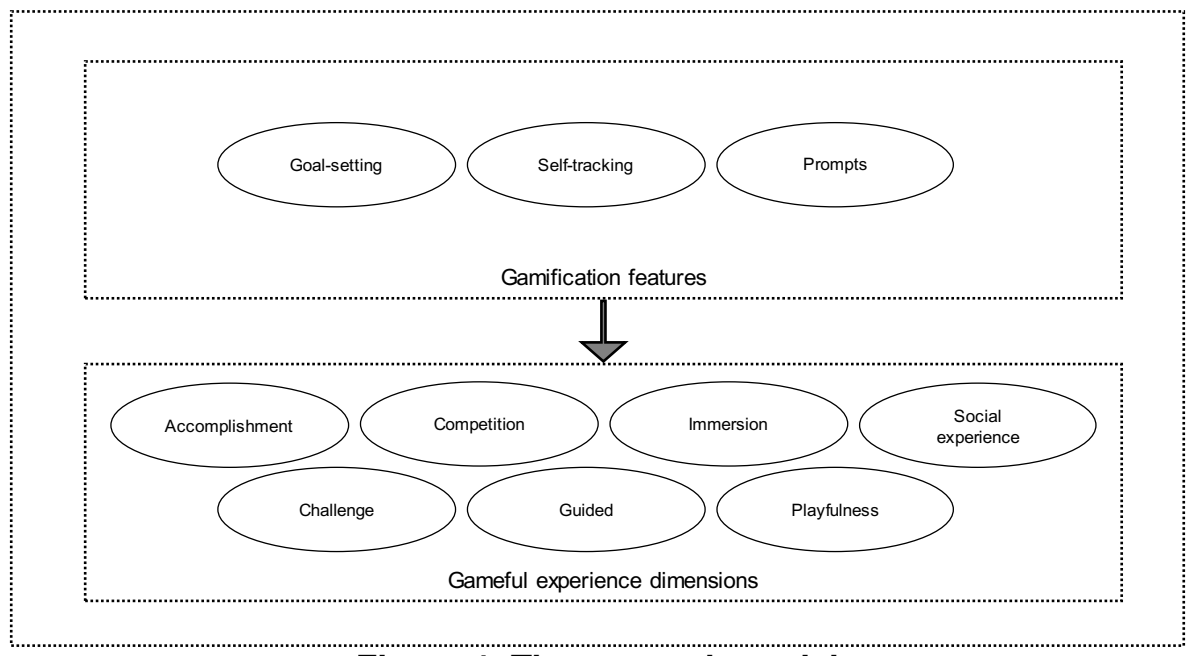

Figure 1. The research model 


\section{The empirical study}

\subsection{Procedure and participants}

An online survey was administered amongst the users $(\mathrm{N}=201)$ of a gamified exercise, and self-tracking app; Wellmo, to investigate the gameful experiences that gamification features are associated with. Wellmo is available for free download on the iOS and Android app stores. It allows users to create profiles, choose a health goal according to their fitness levels and track their progress. As a standard exercise app ${ }^{1}$, it tracks the activity levels of users, daily steps, distance, calories burned, sleep, and alcohol consumed amongst other variables that may be of interest to the users. An automated trainer is available to guide the users through their goals if they so wish. Various trackers and third-party applications and accounts can be connected to the app. Users of the app can compete against each other on who ranks higher on leaderboards based on the points each user collects. The app includes leaderboards, badges and objects/goals as gamification features that support goal-setting; progression and visual feedback as gamification features that support self-tracking, and reminders and suggestions as gamification features that support prompts.

Table 2 provides the demographic information of the study participants. The participants were all either employees or customers of a large Finnish health insurance company. All participants accessed the app through a specific code that was provided to them by the insurance company, however, they were not further segmented once they started using the app and there is no possible way to distinguish them on the app. The survey was placed in-app.

\subsection{Measurement}

The study participants were asked to estimate the importance and frequency of use of the gamification features (see [51]) using a 7-point Likert scale $(1=$ completely unimportant, $7=$ very important), and a 7 point Likert scale $(1=$ interacting with the feature rarely, $3=$ interacting with the feature less than $30 \%$ of the times, $5=$ interacting with the feature less than

\footnotetext{
${ }^{1}$ The persuasive/motivational design of e.g. exercise and other wellbeing apps is considered to belong under the large umbrella of gamification [18, 19, 21, 28, 31, 32], however, it perhaps remains debatable to what degree they all are game-like. In this study, we cover all the interface elements of the target gamified exercise system that are related to supporting the users in their exercise and well-being. For the sake of simplicity, we refer to the total set of features herein as "gamification features". Appendix 1 details these features.
}

$70 \%$ of the times, $7=$ interacting with the feature every time) respectively. The measurement of gameful experience was adapted from the GAMEFULQUESTinstrument by Högberg et al. [22], which can be used to measure a user's perceived gameful experience of a system. At the planning stage of the research, researchers went through the measuring items in the instruments to ensure that they were all applicable to the study context. A leading prefix "This app makes me feel..." was added to the start of measuring item, as indicated in Appendix 1, to ensure the participants were thinking of the investigated app as they answered.

Seven dimensions of gameful experience were measured as defined in Appendix 1: accomplishment (8 items), challenge ( 7 items), competition ( 7 items), guided (6 items), immersion (9 items), playfulness (9 items) and social experience ( 7 items). All of the seven dimensions of gameful experience were measured on a 7-point Likert scale, ranging from 1 (strongly disagree) to 7 (strongly agree). The application was used in Finnish language in Finland. Thus, the survey was translated and administered in Finnish.

\subsection{Validity and reliability}

Following the guidelines of Cenfetelli and Bassellier [38], the measured use frequency and importance of each of the three investigated gamification feature sets were conceptualized as formative constructs. This is because the use frequency and importance of each feature is posited as the cause of the measured construct. On the other hand, the seven dimensions of gameful experience were conceptualized as reflective constructs given that their indicators are assumed to be caused by the latent variables. Model testing was done through SmartPLS 3.0 as described below.

The formative measurement model: The validity of the formative model was assessed through examining multicollinearity as well as indicator loadings and weights. Multicollinearity was assessed through an examination of the Variance Inflation Factors (VIFs). The formative measurement model is presented in Appendix 1. All VIF values are significantly below the acceptable threshold of $5[4,11,42]$, indicating no multicollinearity between the items. All indicators have high loadings, and even though the weights of some items (e.g., Object/Goal_2) are lower than 0.5 and may be insignificant, the loadings of the corresponding items are quite high. The formative measurement model, hence, has an acceptable external validity. 
Table 2. Demographic information

\begin{tabular}{|c|c|c|c|c|c|c|c|}
\hline \multicolumn{2}{|l|}{ Variable } & \multirow{2}{*}{$\frac{\mathbf{N}}{78}$} & \multirow{2}{*}{$\begin{array}{c}\% \\
38.8\end{array}$} & \multicolumn{2}{|l|}{ Variable } & \multirow{2}{*}{$\begin{array}{c}\mathbf{N} \\
19\end{array}$} & \multirow{2}{*}{$\begin{array}{c}\% \\
9.5\end{array}$} \\
\hline Gender & Male & & & Annual household & Under 20.000 & & \\
\hline & Female & 123 & 61.2 & income & $20.001-29.999$ & 16 & 8.0 \\
\hline \multirow[t]{7}{*}{ Age } & Under 20 & 0 & 0.0 & & $30.000-39.999$ & 26 & 12.9 \\
\hline & $20-29$ & 40 & 19.9 & & $40.000-49.999$ & 25 & 12.4 \\
\hline & $30-39$ & 77 & 38.3 & & $50.000-74.999$ & 65 & 32.3 \\
\hline & $40-49$ & 56 & 27.9 & & $75.000-99.999$ & 29 & 14.4 \\
\hline & $50-59$ & 23 & 11.4 & & $100.000-149.999$ & 15 & 7.5 \\
\hline & $60-69$ & 4 & 2.0 & & Over 150.000 & 6 & 3.0 \\
\hline & 70 or more & 1 & 0.5 & \multicolumn{2}{|c|}{ Living circumstances Alone } & 20 & 10.0 \\
\hline \multirow[t]{6}{*}{ Employment } & Full-time & 162 & 80.6 & & With a partner & 63 & 31.3 \\
\hline & Part-time & 11 & 5.5 & & With friend(s) & 2 & 1.0 \\
\hline & Unemployed & 7 & 3.5 & & With family & 116 & 57.7 \\
\hline & Students & 6 & 3.0 & \multirow[t]{5}{*}{ Use Length } & Less than a month & 22 & 10.9 \\
\hline & Retired & 4 & 2.0 & & 1-6 months & 72 & 35.8 \\
\hline & Other & 11 & 5.5 & & 6-12 months & 50 & 24.9 \\
\hline \multirow[t]{7}{*}{ Education } & No degree & 3 & 1.5 & & $1-2$ years & 46 & 22.9 \\
\hline & Upper secondary & 8 & 4.0 & & More than 2 years & 11 & 5.5 \\
\hline & Vocational (or equivalent) & 86 & 42.8 & \multirow[t]{5}{*}{ Use frequency } & More than once a day & 22 & 10.9 \\
\hline & Bachelor's (or equivalent) & 71 & 35.3 & & Daily & 72 & 35.8 \\
\hline & Master's or higher degree & 33 & 16.4 & & Several times a week & 50 & 24.9 \\
\hline & & & & & 1 or 2 times a week & 46 & 22.9 \\
\hline & & & & & Less than once a week & 11 & 5.5 \\
\hline
\end{tabular}

The reflective measurement model: We evaluated the reliability and convergent validity of the reflective measurement model by applying Kline's [25] and Fornell \& Larcker's [8] approaches. The reflective measurement model is presented in Appendix 2. Cronbach's $\alpha$ 's of all indicators are higher than 0.9. In addition, the average variance extracted (AVE) is at an acceptable range between 0.662 to 0.908 , and the construct reliability (CR) is between 0.924 to 0.966 . Thus, the reflective measurement model has good convergent validity [8]. For assessing the discriminant validity, the heterotrait-monotrait ratio of correlations (HTMT) is a new method in partial least squares structural equation modeling [12]. In order to clearly discriminate between two factors, the HTMT should be significantly smaller than one [19]. The HTMT values are presented in Appendix 3. HTMT values are between 0.562 and $0.940(\mathrm{P}<0.001)$. Thus the discriminant validity was acceptable in this study.

\subsection{Results}

The investigated model explained $47.4 \%$ of the variance for accomplishment $\left(\mathrm{R}^{2}=0.474\right), 42.6 \%$ of the variance for challenge $\left(\mathrm{R}^{2}=0.426\right), 31.8 \%$ of the variance for competition $\left(\mathrm{R}^{2}=0.318\right), 33 \%$ of the variance for guided $\left(\mathrm{R}^{2}=0.33\right), 23.1 \%$ of the variance for immersion $\left(\mathrm{R}^{2}=0.231\right), 38 \%$ of the variance for playfulness $\left(\mathrm{R}^{2}=0.38\right)$ and $23.4 \%$ of the variance for social $\left(\mathrm{R}^{2}=0.234\right)$. Table 3 presents the structural equation modeling results.

As per the relationship between goal-setting gamification features and the seven dimensions of gameful experience, goal-setting features were significantly associated with the dimensions of accomplishment, challenge, competition, immersion, playfulness and social experience. The relationship between goal-setting features and guided was insignificant $(\beta=0.098, P=0.279)$. Self-tracking gamification features were significantly associated with accomplishment $(\beta=0.3)$, immersion $(\beta=-0.303)$ and social $(\beta=-0.215)$. However, the influences of self-tracking-related features on immersion and social were negative. In terms of the prompts-related gamification features, only the relationship between prompts-related gamification features and competition was insignificant $(\beta=0.164, \mathrm{P}=0.093)$.

\section{Discussion}

This study examined the relationships between three sets of gamification and systems features and gameful experiences. The findings indicate that the features associate differently with the dimensions of the gameful experience that the user derives from the $b$ 
Table 3. The structural equation model results (bootstrapping, sample $=5000$ )

\begin{tabular}{|c|c|c|c|c|c|c|c|c|c|}
\hline & $\beta$ & $\mathbf{P}$ & \multicolumn{2}{|c|}{ CI95\% } & \multicolumn{2}{|r|}{$\beta$} & \multicolumn{3}{|c|}{ CI95\% } \\
\hline GS -> Accomplishment & $0.217 * *$ & 0.006 & 0.081 & 0.390 & ST -> Immersion & $-0.303 * *$ & 0.008 & -0.466 & -0.019 \\
\hline GS -> Challenge & $0.298 * * *$ & 0.000 & 0.140 & 0.471 & ST -> Playfulness & -0.059 & 0.476 & -0.196 & 0.131 \\
\hline GS $->$ Cor & $0.534 * * *$ & 0.000 & 0.349 & 0.695 & ST $->$ Social & $-0.215 *$ & 0.022 & -0.359 & 0.014 \\
\hline GS -> Guided & 0.098 & 0.279 & -0.05 & 0.301 & P -> Accomplishment & $0.281 * * *$ & 0.000 & 0.120 & 0.437 \\
\hline GS -> Immersion & $0.334 * * *$ & 0.000 & 0.164 & 0.510 & P -> Challenge & $0.386 * * *$ & 0.000 & 0.224 & 0.519 \\
\hline $\mathrm{GS}->\mathrm{Pl}$ & $0.305 * * *$ & 0.000 & 0.151 & 0.478 & P -> Competition & 0.164 & 0.093 & -0.036 & 0.353 \\
\hline GS -> Social & $0.339 * * *$ & 0.000 & 0.165 & 0.513 & P -> Guided & $0.449 * * *$ & 0.000 & 0.258 & 0.576 \\
\hline ST-> Accomplishment & $0.300 * * *$ & 0.000 & 0.169 & 0.430 & P -> Immersion & $0.343 * * *$ & 0.000 & 0.132 & 0.506 \\
\hline ST $->$ Challenge & 0.042 & 0.566 & -0.076 & 0.212 & P -> Playfulness & $0.410 * * *$ & 0.000 & 0.239 & 0.538 \\
\hline $\mathrm{ST}->\mathrm{Co1}$ & -0.174 & 0.071 & -0.326 & 0.055 & P -> Social & $0.313 * * *$ & 0.001 & 0.112 & 0.466 \\
\hline $\mathrm{ST}>\mathrm{G}_{1}$ & 0 & & -0.059 & 0.256 & & & & & \\
\hline . & g & & 9 & & & & & & \\
\hline
\end{tabular}

use of a (gamified) system. Goal-setting features had a significant positive association with all dimensions of gamefulness except for the guided experience. While goals differ in the degree of challenge they create $[17,29]$, research around positive experiences and flow indicates that a suitable degree of challenge is enjoyable [5] and provides feelings of accomplishment and success when facing the challenge [7]. Hence, it is unsurprising to observe these associations between goal-setting features and the gameful dimensions of accomplishment, challenge, and immersion. Similarly, it is intuitive to observe associations between goal-setting features and feelings of competition as competition inherently revolves around goals. Goal-setting features, such as leaderboards, allow for social comparison [15], which was indicated in the data by feelings of social presence. Furthermore, an association between goal-setting features and playfulness was also found, suggesting that the competition that is perhaps taking place is none the less playful.

The observations that neither goal-setting nor selftracking features were associated with guided experiences are surprising as one of the main goals of the investigated system is to guide users in the exercise domain. On occasions, goal-setting and self-tracking have been observed to have a lower guidance impact [35], e.g. if the set goals and progress tracking methods are not appropriate for a specific context or when individuals are not very receptive to these methods. Furthermore, the guided dimension of the gameful experience has been conceptualized as an active process of guidance [22]. The app in question sets the goals at the sign-up stage, i.e. without later on providing smaller, more manageable goals, communicated to the users on a weekly or daily basis.
The lack of more active goal-setting might have additionally made self-tracking appear purposeless as it may not have been clear what the tracking was specifically for without such interim goals. Hence, the goal-setting and self-tracking features implemented in the investigated system may not have been appropriate to provide a guided experience. Research is encouraged to compare which goal-setting and selftracking features and larger system designs may be able to provide a guided experience.

Self-tracking features, however, were expectedly positively associated with feelings of accomplishment Nonetheless, self-tracking of one's activity may, as indicated by the negative association between selftracking and immersion and social experiences, break individuals out of immersion and social experiences. Immersion requires focused attention on the activity that is the current source of immersion [5]. Similarly, self-tracking of behavior can distract from social connectedness [47]. Overall, it seems that while selftracking contributes to feelings of gamefulness, excessive self-tracking may, however, be more detrimental than helpful to the creation of a positive, enjoyable experience.

Prompts-related gamification features were positively associated with all dimensions of the gameful experience except with feelings of competition. While individuals differ in the perceived usefulness of phone notifications and prompts [46], in the given context they are not perceived negatively. It is worthy to note here that users of the investigated app had the ability to set the frequency of the prompts they received. Prompts are useful in advising users on what they should do next [35]. They direct the users again to the app that is providing them with feelings of immersion and playfulness, thus strengthening these 
experiences rather than distracting and retracting from them. Similarly, they can provide social information related to the user's social network thus supporting social experiences. The insignificant association between prompt features and competition, however, could be due to the prompts being centered around the individual and thus not necessarily creating a feeling of competition. Nonetheless, this aspect along with the outlined associations are worthy of further investigation.

The results overall suggest the importance of especially goal-setting and prompts in facilitating most dimensions of the gameful experience that is thought to be the essence of gamification design. Designers and system developers are encouraged to consider the conscious utilization of these features to support users in activities where motivation for further engagement is needed. Similarly, the features that support selfregulation may help individuals towards the betterment of themselves through goal-setting and prompts while feeling gameful about the processes, creating both utilitarian and hedonic benefits.

As outlined, experiences of gamefulness differ across individuals, however, due to scope limitations, this research did not consider the role of factors such as age, perception of games, gender, personality, user traits or use tenure on the associations between gamification features and the dimensions of gamefulness. Future research is encouraged to consider the moderating effect of these variables on perceptions of gamefulness in gamified applications.

\section{Acknowledgments}

This work was supported by the Finnish Foundation for Economic Education (grants: 12-6385 and 14-7824), Business Finland (projects: $5654 / 31 / 2018$ and 376/31/2018), the Centre of Excellence on Game Culture Studies (GameCult), Marcus Mallenbergin tutkimussäätiö and Satakunnan Korkeakoulusäätiö and its collaborating organizations

\section{References}

[1] B. Bandura, "Social cognitive theory of selfregulation". Organizational behavior and human decision processes, 50(2), 1991, pp. 248-287.

[2] D. Bormann, and T. Greitemeyer, "Immersed in virtual worlds and minds: effects of in-game storytelling on immersion, need satisfaction, and affective theory of mind". Social Psychological and Personality Science 6(6), 2015, pp. 646-652.

[3] L. E. Burke, J. Wang, and M. A. Sevick, "Selfmonitoring in weight loss: a systematic review of the literature". Journal of the American Dietetic Association 111(11), 2011, pp. 92-102.

[4] R. T. Cenfetelli, and G. Bassellier, "Interpretation of formative measurement in information systems research”. MIS quarterly, 2009, pp. 689-707.

[5] M. Csikszentmihalyi, "Beyond Boredom and Anxiety: Experiencing Flow in Work and Play". The Jossey-Bass Behavioral Science Series. San Francisco: Jossey-Bass, 1975.

[6] S. Deterding, D. Dixon, R. Khaled, and L. Nacke, "From game design elements to gamefulness: defining gamification". Proceedings of the 15th International Academic MindTrek Conference on Envisioning Future Media Environments - MindTrek '11, 2011, ACM, Tampere, Finland, pp. 9-15.

[7] A. J. Elliot, and J. M. Harackiewicz, "Goal setting, achievement orientation, and intrinsic motivation: A mediational analysis". Journal of Personality and Social Psychology 66(5), 1994, pp. 968-980.

[8] C. Fornell, and D. F. Larcker, "Evaluating structural equation models with unobservable variables and measurement error". Journal of Marketing Research 18(1), 1981, pp. 39-50.

[9] I. Granic, A. Lobel, and R. C. Engels, "The benefits of playing video games". American Psychologist 69(1), 2014.

[10] G. F. Tondello, H. Premsukh, and L. E. Nacke, “A Theory of Gamification Principles Through GoalSetting Theory". Proceedings of the 51st Hawaii International Conference on System Sciences (HICSS51), 2018.

[11] J. F. Jr. Hair, R. E. Anderson, R. L. Tatham, and W. C. Black. "Multivariate Data Analysis", 3rd ed. New York: Macmillan, 1995.

[12] J. F. Hair, G. T. M. Hult, C. M. Ringle, and M. Sarstedt, "A Primer on Partial Least Squares Structural Equation Modeling (PLS-SEM)", 2nd Ed., Thousand Oakes, CA: Sage, 2017.

[13] J. Hamari, Gamification. Wiley Blackwell Encyclopedia of Sociology (in press), 2019.

[14] J. Hamari, L. Hassan, and A. Dias, "Gamification, quantified-self or social networking? Matching users' goals with motivational technology". User Modeling and User-Adapted Interaction 28(1), 2018 pp. 35-74.

[15] J. Hamari, and J. Koivisto, "“Working out for likes": An empirical study on social influence in exercise gamification". Computers in Human Behavior 50, 2015a, pp. 333-347.

[16] G. Richter, D. R. Raban and s. Rafaeli, "Tailoring a points scoring mechanism for crowd-based knowledge pooling". Proceedings of the 51st Hawaii International Conference on System Sciences, 2018, pp. 1128-1137.

[17] J. Hamari, D. J. Shernoff, E. Rowe, B. Coller, J. Asbell-Clarke, and T. Edwards, "Challenging games 
help students learn: An empirical study on engagement, flow and immersion in game-based learning". Computers in Human Behavior 54, 2016, pp. $170-179$.

[18] L. Hassan, A. Dias, and J. Hamari, "How motivational feedback increases user's benefits and continued use: A study on gamification, quantified-self and social networking". International Journal of Information Management 46, 2019, pp. 151-162.

[19] J. Henseler, G. Hubona, and P. A. Ray, "Using PLS path modeling in new technology research: updated guidelines". Industrial management \& data systems 116(1), 2016, pp. 2-20.

[20] H. C. Huang, T. T. L. Pham, M.K. Wong, H. Y. Chiu, Y. H. Yang, and C. I. Teng, "How to create flow experience in exergames? Perspective of flow theory". Telematics and Informatics 35(5), 2018, pp. 1288 1296.

[21] K. Huotari, and J. Hamari, "A definition for gamification: anchoring gamification in the service marketing literature". Electronic Markets 27(1), 2017, pp. 21-31.

[22] J. Högberg, J. Hamari, and E. Wästlund, "Gameful Experience Questionnaire (GAMEFULQUEST): An instrument for measuring the perceived gamefulness of system use". User Modelling and User-Adapted Interaction, 2019.

[23] D. Johnson, S. Deterding, K. A. Kuhn, A. Staneva, S. Stoyanov, and L. Hides, "Gamification for health and wellbeing: A systematic review of the literature". Internet interventions 6, 2016, pp. 89-106.

[24] K. Kiili, "Digital game-based learning: Towards an experiential gaming model". The Internet and Higher Education 8(1), 2005, pp. 13-24.

[25] R. B. Kline, "Principles and Practice of Structural Equation Modeling”. New York, Guilford Press, 1998.

[26] J. Koivisto, and J. Hamari, "The Rise of Motivational Information Systems: A Review of Gamification Research". International Journal of Information Management 45, 2019a, pp. 191-210.

[27] J. Koivisto, and J. Hamari, "Gamification of physical activity: A systematic literature review of comparison studies". Proceedings of GamiFIN 2019 conference, Levi, Finland, 2019b, pp. 106-117.

[28] R. N. Landers, "Developing a theory of gamified learning: Linking serious games and gamification of learning". Simulation \& Gaming 45(6), 2014, pp. 752768.

[29] R. N. Landers, K. N., Bauer, and R. C. Callan, "Gamification of task performance with leaderboards: A goal setting experiment". Computers in Human Behavior 71, 2017, pp. 508-515.

[30] R. N. Landers, E. M. Auer, A. B. Collmus, and M. B. Armstrong, "Gamification Science, Its History and
Future: Definitions and a Research Agenda". Simulation \& Gaming 49(3), 2018a, pp. 315-337.

[31] R. N. Landers, G. F. Tondello, D. L. Kappen, A. B. Collmus, E. D. Mekler, and L. E. Nacke, "Defining gameful experience as a psychological state caused by gameplay: Replacing the term 'Gamefulness' with three distinct constructs". International Journal of Human-Computer Studies, 2018b.

[32] G. P. Latham, and E. A. Locke, "Self-regulation through goal setting". Organizational behavior and human decision processes 50(2), 1991, pp. 212-247.

[33] E. A. Locke, K. N. Shaw, L. M. Saari, and G. P. Latham, "Goal setting and task performance: 19691980”. Psychological Bulletin 90(1), 1981.

[34] E. A. Locke, G. P. Latham, and A. Edwin, "Building a practically useful theory of goal setting and task motivation: A 35-year odyssey". American Psychologist 57(9), 2002, pp. 705-717.

[35] D. Lupton, "The Quantified Self: A Sociology of Self-Tracking”. Cambridge: Polity Press, 2016.

[36] G. Richter, D. R. Raban, and S. Rafaeli, "Studying gamification: The effect of rewards and incentives on motivation". Gamification in education and business, 2015, pp. 21-46, Springer International Publishing.

[37] A. Anderson, D. Huttenlocher, J. Kleinberg, and J. Leskovec. "Steering user behavior with badges". Proceedings of the 22nd International Conference on World Wide Web, 2013, pp. 95-106.

[38] R. T. Cenfetelli, and G. Bassellier, "Interpretation of Formative Measurement in Information Systems Interpretation of Formative Measurement in Information Systems Research". MIS Quarterly, 33(4), 2009, pp. 689-707

[39] S. Munson, and S. Consolvo, "Exploring Goalsetting, Rewards, Self-monitoring, and Sharing to Motivate Physical Activity". Proceedings of the 6th International Conference on Pervasive Computing Technologies for Healthcare, IEEE, 2012 pp. 25-32..

[40] J. Nunnally, "Psychometric methods". McGrawHill, New York, 1978.

[41] W. Peng, J. C. Crouse, and J. H. Lin, "Using active video games for physical activity promotion: a systematic review of the current state of research". Health education \& behavior 40(2), 2013, pp. 171-192. [42] C. M. Ringle, S. Wende, and J. M. Becker, SmartPLS 3. Bönningstedt: SmartPLS. 2015. Retrieved from http://www.smartpls.com

[43] M. Sailer, J. U. Hense, S. K. Mayr, and H, Mandl, "How gamification motivates: An experimental study of the effects of specific game design elements on psychological need satisfaction". Computers in Human Behavior, 69, 2017, pp. 371-380.

[44] L. Sardi, A. Idri, and J. L. Fernández-Alemán, “A systematic review of gamification in e-Health". Journal of biomedical informatics 71, 2017, pp. 31-48. 
[45] K. Seaborn, and D. I. Fels, "Gamification in theory and action: A survey". International Journal of human-computer studies 74, 2015, pp. 14-31.

[46] A. S. Shirazi, N. Henze, T. Dingler, M. Pielot, D. Weber and A. Schmidt, "Large-scale assessment of mobile notifications". Proceedings of CHI Vol. 14, 2014, pp. 3055-3064.

[47] M. Snyder, "Self-monitoring processes". Advances in experimental social psychology, Vol. 12, Academic Press, 1979, pp. 85-128.

[48] M. Swan, "The Quantified Self: Fundamental Disruption in Big Data Science and Biological Discovery". Big Data 1(2), 2013, pp. 85-92.

[49] L. Von Ahn, and L. Dabbish, "Designing games with a purpose". Communications of the ACM 51(8), 2008, pp. 58-67.

[50] H. Warmelink, J. Koivisto, I. Mayer, M. Vesa, and J. Hamari, "Gamification of production and logistics operations: Status quo and future directions". Journal of Business Research, 2019.
[51] N. Xi, and J. Hamari, "Does gamification satisfy needs? A study on the relationship between gamification features and intrinsic need satisfaction". International Journal of Information Management 46, 2019, pp. 210-221.

[52] B. J. Zimmerman, "Investigating self-regulation and motivation: Historical background, methodological developments, and future prospects". American educational research journal 45(1), 2008, pp. 166-183.

[53] T. W. Malone, "Toward a Theory of Intrinsically Motivating Instruction”. Cognitive Science, 5(4), 1981, pp. 333-369.

[54] R. M. Ryan, C. S. Rigby, A. Przybylski, "The motivational pull of video games: A self-determination theory approach". Motivation and emotion 30(4), 2006, pp. 344-360.

[55] H. Oinas-Kukkonen, and M. Harjumaa, "Persuasive Systems Design: Key Issues, Process Model, and System Features". Communication of the Association for Information Systems 24(1), 2009, pp.485-500.

\section{Appendices}

\begin{tabular}{|c|c|c|c|c|c|c|c|}
\hline Construct/Items ${ }^{\mathrm{a}}$ & Loading & Weight & VIF & Construct/Items & Loading & Weight & VIF \\
\hline \multicolumn{4}{|c|}{ Self-tracking-related gamification features } & \multicolumn{4}{|c|}{ Goal setting-related gamification features } \\
\hline Progression_1 & 0.955 & 0.528 & 3.733 & Badge_1 & 0.801 & 0.187 & 3.443 \\
\hline Progression_2 & 0.623 & 0.054 & 2.069 & Badge_2 & 0.873 & 0.441 & 2.780 \\
\hline Visual feedback_1 & 0.947 & 0.437 & 3.915 & Leaderboard_1 & 0.686 & -0.063 & 2.890 \\
\hline Visual feedback_2 & 0.588 & 0.083 & 2.074 & Leaderboard_2 & 0.781 & 0.424 & 2.306 \\
\hline \multicolumn{4}{|c|}{ Prompts-related gamification features } & Object/Goal_1 & 0.708 & 0.325 & 2.344 \\
\hline Remind_1 & 0.715 & -0.015 & 2.430 & Object/Goal_2 & 0.440 & -0.120 & 1.774 \\
\hline Remind_2 & 0.837 & 0.571 & 2.131 & & & & \\
\hline Suggestion_1 & 0.827 & 0.559 & 2.397 & & & & \\
\hline Suggestion 2 & 0.740 & 0.096 & 2.087 & & & & \\
\hline
\end{tabular}

${ }^{\mathrm{a}} \mathrm{X} \_1$ = frequency of using $\mathrm{X}$ gamification feature; $\mathrm{X} \_2$ = importance of $\mathrm{X}$ gamification feature

\section{Appendix 2. The reflective measurement}

\begin{tabular}{|c|c|c|c|c|}
\hline \multicolumn{2}{|c|}{ Construct/item } & \multicolumn{2}{|c|}{ Loading Construct/item } & \multirow[t]{2}{*}{ Loading } \\
\hline \multicolumn{4}{|l|}{ This app } & \\
\hline \multicolumn{3}{|c|}{ Accomplishment $(\alpha=0.96 C R=0.966 \mathrm{AVE}=0.782)$} & \multicolumn{2}{|l|}{ Immersion $(\alpha=0.914 C R=0.928$ AVE $=0.590)$} \\
\hline $\mathrm{ACC}_{-} 1$ & $\begin{array}{l}\text { makes me feel that I need to complete } \\
\text { things. }\end{array}$ & 0.819 & $\begin{array}{l}\text { IMMER_1 gives me the feeling that time passes } \\
\text { quickly. }\end{array}$ & 0.742 \\
\hline ACC_2 & $\begin{array}{l}\text { pushes me to strive for } \\
\text { accomplishments. }\end{array}$ & 0.881 & IMMER_2 grabs all my attention. & 0.766 \\
\hline $\mathrm{ACC} \_3$ & $\begin{array}{l}\text { inspires me to maintain my standards } \\
\text { of performance. }\end{array}$ & 0.904 & \multicolumn{2}{|c|}{$\begin{array}{l}\text { IMMER_3 gives me a sense of being separated from } 0.677 \\
\text { the real world. }\end{array}$} \\
\hline ACC_4 & $\begin{array}{l}\text { makes me feel that success comes } \\
\text { through accomplishments. }\end{array}$ & 0.903 & $\begin{array}{l}\text { IMMER_ } 4 \text { makes me lose myself in what I am } \\
\text { doing. }\end{array}$ & 0.870 \\
\hline ACC_5 & $\begin{array}{l}\text { makes me strive to take myself to the } \\
\text { next level. }\end{array}$ & 0.904 & $\begin{array}{l}\text { IMMER_5 makes my actions seem to come } \\
\text { automatically. }\end{array}$ & 0.662 \\
\hline ACC_6 & $\begin{array}{l}\text { motivates me to progress and get } \\
\text { better. }\end{array}$ & 0.908 & $\begin{array}{l}\text { IMMER_6 causes me to stop noticing when I get } \\
\text { tired. }\end{array}$ & 0.788 \\
\hline $\mathrm{ACC}_{-} 7$ & makes me feel like I have clear goals. & 0.908 & $\begin{array}{l}\text { IMMER_7 causes me to forget about my everyday } \\
\text { concerns. }\end{array}$ & 0.815 \\
\hline
\end{tabular}




\begin{tabular}{|c|c|c|c|c|}
\hline ACC_8 & $\begin{array}{l}\text { gives me the feeling that I need to } \\
\text { reach goals. }\end{array}$ & 0.842 & IMMER_8 makes me ignore everything around me. & 0.749 \\
\hline \multicolumn{3}{|c|}{ Challenge $(\alpha=0.907 C R=0.926$ AVE $=0.643)$} & IMMER_9 gets me fully emotionally involved. & 0.818 \\
\hline CHAL_1 & makes me push my limits. & 0.776 & Playfulness $(\alpha=0.91 C R=0.924$ AVE $=0.575)$ & \\
\hline $\mathrm{CHAL}_{2} 2$ & $\begin{array}{l}\text { drives me in a good way to the brink } \\
\text { of wanting to give up. }\end{array}$ & 0.681 & PLAY_1 gives me an overall playful experience. & 0.810 \\
\hline CHAL_3 & $\begin{array}{l}\text { pressures me in a positive way by its } \\
\text { high demands. }\end{array}$ & 0.831 & PLAY_2 leaves room for me to be spontaneous. & 0.731 \\
\hline CHAL_4 & challenges me. & 0.865 & PLAY_3 taps into my imagination. & 0.753 \\
\hline CHAL_5 & $\begin{array}{l}\text { calls for a lot of effort in order for me } \\
\text { to be successful. }\end{array}$ & 0.741 & PLAY_4 makes me feel that I can be creative. & 0.760 \\
\hline CHAL_6 & $\begin{array}{l}\text { motivates me to do things that feel } \\
\text { highly demanding. }\end{array}$ & 0.854 & $\begin{array}{l}\text { PLAY_5 gives me the feeling that I explore } \\
\text { things. }\end{array}$ & 0.731 \\
\hline CHAL_7 & $\begin{array}{l}\text { makes me feel like I continuously } \\
\text { need to improve in order to do well. }\end{array}$ & 0.846 & PLAY_6 feels like a mystery to reveal. & 0.711 \\
\hline \multicolumn{3}{|c|}{ Competition $(\alpha=0.926 C R=0.940$ AVE $=0.690)$} & PLAY_7 gives me a feeling that I want to know & 0.787 \\
\hline COMP_1 & $\begin{array}{l}\text { feels like participating in a } \\
\text { competition. }\end{array}$ & 0.844 & $\begin{array}{l}\text { PLAY_ } 8 \text { makes me feel like I discover new } \\
\text { things. }\end{array}$ & 0.805 \\
\hline COMP_2 & inspires me to compete. & 0.836 & PLAY_9 appeals to my curiosity. & 0.733 \\
\hline COMP_3 & $\begin{array}{l}\text { involves me by its competitive } \\
\text { aspects. }\end{array}$ & 0.815 & \multicolumn{2}{|l|}{ Social experience $(\alpha=0.927 C R=0.941 A V E=0.697)$} \\
\hline COMP_4 & makes me want to be in first place. & 0.839 & $\begin{array}{l}\text { SOCO_1 gives me the feeling that I'm not on my } \\
\text { own. }\end{array}$ & 0.784 \\
\hline COMP_5 & makes victory feel important. & 0.837 & SOCO_2 gives me a sense of social support. & 0.808 \\
\hline COMP_6 & feels like being in a race. & 0.866 & $\begin{array}{l}\mathrm{SOCO}_{-} 3 \text { makes me feel like I am socially } \\
\text { involved. }\end{array}$ & 0.875 \\
\hline COMP_7 & $\begin{array}{l}\text { makes me feel that I need to win to } \\
\text { succeed. }\end{array}$ & 0.773 & $\begin{array}{ll}\text { SOCO_4 gives me a feeling of being connected to } \\
\text { others. }\end{array}$ & 0.838 \\
\hline \multicolumn{3}{|c|}{ Guided $(\alpha=0.932 C R=0.947$ AVE $=0.748)$} & SOCO_5 feels like a social experience. & 0.893 \\
\hline GUI_1 & makes me feel guided. & 0.838 & $\begin{array}{l}\text { SOCO_6 gives me a sense of having someone to } \\
\text { share my endeavors with. }\end{array}$ & 0.867 \\
\hline GUI_2 & gives me a sense of being directed. & 0.877 & SOCO_7 influences me through its social aspects. & 0.770 \\
\hline GUI_3 & $\begin{array}{l}\text { makes me feel like someone is } \\
\text { keeping me on track. }\end{array}$ & 0.901 & & \\
\hline GUI_4 & $\begin{array}{l}\text { gives me the feeling that I have an } \\
\text { instructor. }\end{array}$ & 0.872 & & \\
\hline GUI_5 & $\begin{array}{l}\text { gives me the sense I am getting help } \\
\text { to be structured. }\end{array}$ & 0.841 & & \\
\hline GUI_6 & $\begin{array}{l}\text { gives me a sense of knowing what I } \\
\text { need to do better. }\end{array}$ & 0.859 & & \\
\hline
\end{tabular}

Appendix 3. HTMT value for discriminant validity (complete bootstrapping, sample $=5000$ )

\begin{tabular}{|c|c|c|c|c|c|c|c|}
\hline & Accomplishment & Challenge & Competition & Guided & Immersion & Playfulness & Social \\
\hline \multicolumn{8}{|c|}{ Accomplishment } \\
\hline Challenge & 0.940 & & & & & & \\
\hline Competition & 0.704 & 0.901 & & & & & \\
\hline Guided & 0.879 & 0.897 & 0.792 & & & & \\
\hline Immersion & 0.562 & 0.784 & 0.850 & 0.720 & & & \\
\hline Playfulness & 0.826 & 0.940 & 0.898 & 0.913 & 0.903 & & \\
\hline Social & 0.617 & 0.807 & 0.855 & 0.814 & 0.855 & 0.897 & \\
\hline
\end{tabular}

